\title{
Dance/Movement Therapists of Color in the ADTA: The First 50 Years
}

\author{
Meg H. Chang ${ }^{1}$
}

Published online: 19 October 2016

(C) American Dance Therapy Association 2016

\begin{abstract}
One of a collection of six scholarly essays solicited by this journal to celebrate the first half-century of the American Dance Therapy Association, this paper looks at current practices in dance therapy education, clinical practice, and professional leadership as inclusive of, or excluding to, individuals who identify as a person of color. Recommendations for more inclusive attitudes and practices are provided.
\end{abstract}

Keywords Dance/movement therapy supervision - Multicultural practice $\cdot$ Diverse and inclusive education · Dance/movement therapy education · Dance

The journal editors have graciously asked me to write an essay about people of color (POC) and dance/movement therapy (DMT) at this juncture of 50 years of the American Dance Therapy Association's (ADTA's) organizational life. As a person who identifies as being "of color" and having written about, initiated conversations, and advocated for diversity and multicultural inclusion since 1982 (Chang, 1982, 2000, 2002, 2015), I am deeply appreciative that such an opportunity exists. I also appreciate the generous colleagueship of many other dance/movement therapists who are working in this contested arena. Specifically, thanks to Angela Greyson, Maria Rivera, Hilda Wengrower, and Lysa Monique Jenkins-Hayden for comments on this article, and Kiki Nishida, Elissa White, Warin Tepayayone, and Forestine Paulay for conversations that have inspired and fortified me.

Meg H. Chang

meg.chang@umassmed.edu

1 Center for Mindfulness, University of Massachusetts Medical School, 222 Maple Ave., Shrewsbury, MA 01655, USA 
Understanding the ways that life experiences and personal history shape our racial, gendered, cultural, and ethnic identity is one of the key principles underlying the development of cultural competence, defined as "the ability to understand, appreciate, and interact with people of cultures [races] or belief systems different from one's own" (Sue in DeAngelis, 2015). In that spirit, the life perspective that influences my comments here are those of a biracial Chinese (Shanghainese) and Midwestern American (British ancestry) cisgender woman born in the last midcentury into an educationally privileged but economically marginal family on the East Coast of the United States. This, then, is the identity that looks at what has changed over 50 years regarding people who identify as "of color" in the ADTA. As a dance/movement therapist, I have been honored to serve on the ADTA Board of Directors under three different presidents. Such inclusion has heightened a (possibly Confucian) sense of responsibility towards the DMT field. How we as a profession relate to our own and others' race, culture, gender, ethnicity, class, and able-bodiedness is urgently important. Inclusion is demonstrated by the way in which our field sets standards and manages disagreement - and whether we respond to challenges to be inclusive or miss those opportunities entirely. As an educator I acknowledge the privilege I had when teaching in graduate DMT and somatic psychology programs, yet often the only person of color in the room. In this role I have sought out ways that DMT students can bring all of who they are, in all the ways that they identify - even those "subjugated identities" as Ken Hardy says (2016) to their education and hence to their clients and the public. Therefore, this essay focuses on graduate education and the professional development of dance/movement therapists in the U.S., including students from other countries who are perceived as ethnically, culturally, or racially different when they come to study in the U.S.

One obvious change in the past 50 years is that there are now consistently more graduate students "of color" entering DMT programs-people who visibly appear to be from an African-American, Arab-Muslim, Latina/Latino, Native American, or South or East Asian/Asian-American background-many more than there were when I attended Hunter College, 1977-1979. Also changed is the attention paid to race, culture, and to some extent gender, difference in graduate education. In the period from the 1970s through the 1990s, the field was predominantly WhiteEuropean in appearance and in dance forms: Laban's movement taxonomy was the uncontested norm, and conventional Western psychology's hegemonic assumptions had not yet been challenged in counseling or psychotherapy. Consequently, the pernicious intersection of socioeconomic inequity, race, gender, and sexualidentity placed any blame for non-normative thinking, feeling, and acting on the individual, who was often pathologized or silenced. With the notable exception of Irma Dosamantes' contributions to DMT praxis (1997a, 1997b, 1999), Forestine Paulay and Irmgard Bartenieff's ethnography (in Paulay \& Lomax, 1977), and anthropological perspectives provided by Fancizca Boas (1944/1972) and Judith Lynne Hanna (1990, 2006), sociocultural background was largely ignored in DMT.

There is now heightened student awareness of the impact of racial, cultural, and gender identity, and new educational guidelines for graduate DMT programs are 
written to emphasize inclusion. There is a growing awareness that structural racial inequities negatively impact health (Marmot, 2005). Graduate DMT programs now strive, with varying degrees of commitment and student satisfaction, for cultural competency in syllabi and supervision. Most importantly, there is the beginning of a dialogue - talking together about the difficulties and joys - and a recognition of the need for having the difficult conversations (McGoldrick \& Garcia-Preto, 2005). To the extent that members of the ADTA, educators, those new to the field, and colleagues around the world are exploring how privilege (McIntosh, 1988), structural racism (Adams \& Bell, 2007), colorism (Hunter, 2007), microaggression (Sue et al., 2007), stereotype threat (Steele, 2010), colonialism (Back \& Solomos, 2000), and gender identity (Meyers, 1997) — not to forget ableism (Longmore \& Umansky, 2001; Caldwell, 2013), misogyny (Meyers, 1997), and heterosexism (Meyers, 1997)—manifest in our professional and personal lives, DMT becomes more resilient, inclusive, and a force for change within our own community and towards those we serve.

Since 1966, structural changes within the ADTA include updating graduate educational standards and making substantive changes to the ethical standards. Elissa Queyquep White (who identifies as "Filipina and Jewish," personal communication, November 11, 1998) was elected as our first president of color, and the ADTA Board of Directors has added a Multicultural and Diversity Committee. Affinity groups representing students and clinicians from AfricanAmerican, Latino, White Allies, Asian \& Asian-American, and LBGTQA (JenkinsHayden, 2015; Greyson, 2015) communities have a voice and a place to share unique experiences. Workshops and seminars presented at the ADTA's annual conference address diversity and multicultural applications; and a full scholarship to the conference is provided to a self-identified multicultural or gender-diverse student or beginning clinician, funded through member donations to the annual conference scholarship. Such organizational improvement is establishing new norms with a goal of fostering a more inclusive and welcoming climate.

There has been less change in the tacit understandings of "systems and structures that have evolved, for centuries, to privilege and to subordinate, all based on race and color" (Magee, in press). The culture of the ADTA's founders reflected a particular time and set of social conditions that reified the water of privilege in which our predominately female, heterosexual, White, upper middle-class, and urban profession, still swims (Bourdieu, 1991). The habitus of privilege is to be taken for granted as "natural." A durable example is evident in the ratio of faculty of color to White European faculty. Statistically, little has changed since Elissa Queyquep White and Irma Dosamantes were on the dance therapy faculty of Hunter College and University of California, Los Angeles, respectively. When faculty of color are not evident in higher education, there is lower student of color retention, and the burden of pointing out microinsults, and bearing microassaults (Sue, 2003), and cultural misunderstandings falls upon those individuals who are already in the racial minority. These students, faculty, and emerging professionals of color may feel and experience being "othered" for maintaining cultural identities that look, sound, or dance differently, and who hold contrasting beliefs from the power structure of their institutions. Compounding such microaggressions, the worldview 
of POC is minimized and made invisible through colorblind platitudes. Particularly in the arts, cultural artifacts, dances, and expressions are appropriated and promoted as novel and exciting (Picart, 2013; Unruh, 2011).

It is possible that between 40 and 50 years ago, as the field was being developed, there was more openness to self-examination and social activism (Schmais, 1999). If so, where are we now when compared to 1966? What happened to the AfricanAmerican dance therapists who joined in co-founding the ADTA? Why are the Spanish-speaking founding members disaffiliated? Have predominant attitudes towards "passive" East Asian students changed, really (Pallaro, 1997)? More importantly, after 50 years of reflecting, what needs to change? In the 1970s, when DMT education embraced a systems perspective (Birdwhistell, 1970; Bateson, 1972), the field was attuned to the broader social environment. As Blanche Evan frequently stated, "Thought without action is the great perpetrator of the neurotic life" (Evan, 1976).

The following examples were generated from graduate and alternate route DMT programs, with students who identify as different regarding race, gender, class, or culture. As personal and immediate actions, the following recommendations apply equally well to all dance therapists. Students and professional dance/movement therapists continue to experience subtle and unconscious racial, cultural, gender, and ethnic bias within the classroom and clinical setting from faculty, other students, and clinical supervisors (Phelps et al, 2000; Jenkins-Hayden, 2011; Greyson, 2015). Steps toward reducing disruptive microaggressions in the form of thoughtless microinsults: " $[\mathrm{H}] \mathrm{e}$ tells you his dean is making him hire a person of color when there are so many great writers out there" (Rankine, 2014, p. 10), and unconscious microinvalidations, such as not being called on as frequently as a White or European speaker in a classroom or in group setting are not uncommon.

\section{Recommendations: At the Personal and Individual Level}

- Acknowledge and speak to the historical power differentials of race, culture, and ethnicity, especially as these intersect with gender, class, and able-bodiedness in the classroom; this will lead to greater facility in the treatment room. In clinical practice, as well as education, we need to be alert to how debilitating it is to hide or minimize such essential elements of body image and self.

- It follows that identity and identifiers belong to the subject. Despite the tendency for a member of the dominant group to objectify and name the other-"What kind of Asian are you?" (helpmefindparents, 2013), "Funny, you don't look ", or "Where are you from, really?"-it is the person of color who makes the choice of how to self-identify and self-authorize. It is a presumptuous form of microaggession for someone who is recognizably from the dominant group to feel authorized to make assumptions about POC without knowing how the person perceives their own heritage.

- Having to keep silent or be labeled with a microinsult as "the one who always rocks the boat," can motivate a dance therapist of color and difference to look elsewhere for professional community. 
- Issues that arise with more subtle identity manifestations are students whose racial and cultural background is freighted by the concept of "passing." "Passing for White" has been fallaciously construed as a benefit by people who operate from a colorblind perspective. Praising biracial or multiracial persons for having a light skin tone or telling them that they "don't look" like persons of their racial identity can comprise an erasure of identity, of authenticity, of culture, and negates identities linked to ancestors. Failing to understand the conflict this perspective stimulates effectively silences an individual, and amounts to microinvalidation: "Communications that subtly exclude, negate or nullify the thoughts, feelings or experiential reality of a person of color". The struggles this raises for someone with intersecting identities is often ignored or minimized.

- In a similar manner, Asians or Asian-Americans are considered the next group to become assimilated into White privilege. Accrued status presents a risk of undervaluing heritage and identity, either by inducing assimilation or through colorblind assertions.

- For LGBTQ individuals, the intersectionality of color and gender (among other possibilities) raises questions of whether there is safety and encouragement to speak in class, so as to be and represent all of who they are.

- Therefore, for many White Europeans, the need to do our own work means engaging in a rigorous, personal/social, and honest self-investigation into our own racial, cultural, ethnic, and gendered background in order to become more culturally competent (McGoldrick, Giordano, \& Garcia-Preto, 2005). Such a revealing process may require specialized, professional assistance and training. Attaining cultural humility certainly requires consistent reading, self-study, and interrogation of dominant norms surrounding the home we grew up in and the things we heard and came to believe about "others." Similar to the way that dance/movement therapists learn to decipher and experience their own movement preferences, we can bring that same excited discovery to self-study of our own bias. Developing what legal scholar Rhonda Magee calls ColorInsight Practices (Copyright 2015) is a stimulating and on-going process of self-awareness. Similarly, Francine Kendall (2012), who writes about White privilege, recommends that whenever someone uses "Black" as a personal modifier, it is useful to interject "White," in reference to Caucasians, as an equivalent conversational identifier.

- Being the only person of color in any professional setting is isolative. Being "the only" in a class - especially when the espoused norm is colorblind invisibilityon a clinical team, in supervision, or on a professional board can be corrosive and also leads to attrition. To support the only requires recognizing the need to take time to recuperate, to nourish oneself, to not burn out or drop out while doing this work-a regimen of good self-care and prioritization of life-affirming aspects. Such a departure from striving can be supported rather than questioned. 


\section{Recommendations: At the Institutional Level}

- In the ADTA, in the next 5 years, it would be heartening for there to be multiple representatives from diverse racial and cultural backgrounds on the board, as full-time faculty teaching in graduate programs, as clinical supervisors, as community leaders. This acknowledgment and intentionality encourages more students and young professionals to stay in the field as they recognize professors and models who look like them. The same is true of international students.

- Introduce more dance/movement therapists of color to public service and leadership roles and provide well-defined professional mentoring at national and regional levels. Explicit and tangible support is especially necessary for new board and committee members as the tendency is for female intellectuals and trailblazers of color to be "overburdened . . . with duties . . . and committees, advising and mentoring, and outreach and community service . . . hobbled by lack of institutional and financial support . . . and by extreme isolation, overwork, and exhaustion" (Benjamin, 1997, in Priest, 2008).

- The Multicultural and Diversity Committee (MDC) Chair has an unusual crosscutting, cross-functional role. The MDC provides specialized input into the deliberations and processes of the other committees, such as Standards \& Ethics and Education when issues that involve race, culture, or ethnicity are presented by membership. The Chair also serves as an ombudsperson for persons of color throughout the profession. As such, it is critical that the Chair receive commensurate support in resources, whether fiscal or in terms of task participation. In this connection, please note that the Chair functions as a de facto Chief Diversity Officer, a responsibility that is compensated in many organizations comparable to the ADTA. Since the ADTA has a volunteer board, in order to support and promote our members, resources need to be devoted to this committee proportionate to the amount of work required.

\section{Recommendations: At the Clinical Level}

- Be alert to how currents such as those underlying the Black Lives Matter movement can contribute to understanding our clients' lived experience and personal history (Degruy, 2005). In a similar way the impact of the Chinese Exclusion Act on family history helps clinicians understand the etiology of private distress in a more contextual and less individualized way (Boggs \& Kurashige, 2012).

- As educational programs recognize critical issues in students' identity and strengthen students' ability to access all of their uniqueness, their future clients will benefit. Community work becomes more viable as students and beginning clinicians have avenues to relate to people whose lived experiences are very different from theirs because of skin color, gender identity, country of origin, or socioeconomic background. 
- Continue to offer and promote ongoing training and awareness at the individual and ADTA level, until social structures that perpetuate prejudice and bias change to become supportive, inclusive, and equitable.

\section{Recommendations at the Education and Scholarship Level}

- What is most well-received by students of color, besides faculty of color, are DMT graduate programs and faculty that actively, and independent of accreditation requirements, engage in continuing education and clinical supervision with the specific intention of becoming culturally competent (Schelly-Hill \& Goodill, 2005). Clinical creative arts therapy supervisors who were trained in the past millennium, when the best practice was to be colorblind (as in, "I don't see color!" or "Everyone is the same to me."), also benefit personally and professionally from self-study, perhaps in conjunction with dance therapy programs. Knowing "where we come from" provides a common ground for conversation with supervisees who identify as racially, culturally, ethnically, gendered, or different due to class background.

- A sociocultural framework is needed to grasp the intersectionality of gender, race, culture, class, ethnicity, language, and able-bodiedness. One fertile model comes from the interdisciplinary and multicultural work of Monica McGoldrick and Nydia Garcia-Preto, family therapists trained by Murray Bowen and Betty Carter (McGoldrick, Garcia-Preto, \& Carter, 2011).

- Recognize long-standing cultural/racial healing forms of dance such as Bomba (Rivera, 2008; Concepcion, 2015). Engage in finding creative ways to acknowledge and relate to representatives of indigenous healing forms without improperly appropriating them or their work (Harris, 2010). Develop cultural humility and promote recognition of local teachers.

- Acknowledge that DMT emphasizes individualistic values of the Global North through dance forms, body use, language, music, use of space, and how emotions are expressed. Being open to dance and movement possibilities in countries and cultures with different political structures, psychophysical habitus (Chang, 2002), and language can augment and improve our understanding of how dance heals.

- Be alert to unconscious tendencies to dominate as a White person, to speak first, assign meaning, and take over; instead be curious, be humble.

The ignorance of colorblind racism and the microaggressions and defensive attitudes that are perpetuated can be addressed; steps to become more inclusive, stronger, and speak with one voice are being taken, to build on the vision of 50 years ago. More nuanced understanding of personal and social history underlying the inclusivity of the term POC reduces the Black-White binary of discrimination and permits us to see the whole cloth-to see what we all have at stake. 


\section{Conclusion: Beyond Remediation}

This assessment has called for an infusion of self-examination and a perspective shift (Mezirow, 1991) to bring the consciousness, policies, and programming of the ADTA — as the leader in DMT education and application — into alignment with best practices and contemporary scholarship. A diverse membership benefits from multicultural education and is motivated to sustain an equitable and inclusive organization. As dance/movement therapists, we know the struggle for dance and the body to be acknowledged as respected forms of intelligence and that the most effective way to appreciate the power of dance is to experience it directly. Just so, to repair bias in education and clinical practice, we must investigate our own cultural history and our personal relationship to the historical conditions that have led to hierarchical distinctions and power differentials.

Paradoxically, when di-contextualized (Birdwhistle, 1970), the term people of color, can become another superficial designation with the potential of isolating and stigmatizing those who are different. Merely thinking additively, of POC and DMT, brings to mind simplistic solutions such as "add water and stir," as if all that was needed was to mix in more "of them" to create an integrated field and representative professional association. Such a one-dimensional solution assumes that the Global North aesthetic and power structure is the genuine discipline, and the worldview and leadership of POC is auxiliary - only to be added if there is time. Not only does this evade a substantive discussion of historical and economic inequity and hegemonic authority, but until there is direct first-hand knowledge of race, gender, class, culture, and ethnic identity as each of us lives it, unconscious projections based on unexamined status and privilege will prevail. Another problem is that a topical identifier separates international students from those who do identify as of color. A distinctly American term, it is frequently off-putting to students and professionals from Asia, India, Israel, Palestine, and Arab or Muslim nations (among others) who do not self-identify in that way, or who do not perceive race as the primary demarcation. In many countries class distinctions are more salient. South Asians, East Asians, and Asian-Americans who are perceived as "foreigners" regardless of years of residence in the United States (Nishida, 2008) have long had to choose whether to sit in the front or the back of the bus (Boggs \& Kurashige, 2012).

The continuing globalization of the ADTA (Dulicai \& Berger, 2005) is an opportunity to weigh often-cited platitudes about the universalism (Stock, 2001) of dance and DMT against unconscious colonialist attitudes that perpetuate historic power differentials surrounding race, culture, and language. A fascination with dance from around the world has been a foundation of modern dance and DMT since our profession's beginnings (Boas, 1944/1977; Levy, 1992; Lomax, Bartenieff, \& Paulay, 1974). With instant globalization available through cell phones, it is time to acknowledge the exotification of dance from other cultures along with the projections and stereotypes attached to those who dance the local dances. Owing to the history of colonization and domination, the assumption that a trained dancer from outside the culture can learn any dance and blend it into a dance therapy 
session can be insulting to the person whose dance culture has been appropriated. Therefore, in addition to honoring traditional teachers and always naming and giving credit to the originator of the dance, we need to learn enough about the culture from which the dance came to pass along some understanding of the meaning of the dance (Kealiinohomoku, 1983).

Still another option is to invite equal collaboration in partnership with dancers and dance therapists who live the tradition. The ADTA can expand its identity to include a multiplicity of life-perspectives and the many dance avenues that bring healing to individuals, interpersonal relationships, and communities. Through the kind of group process and respect for individual creativity that is inherent in the discipline of DMT, we are finding ways to share power, learn new dances, and "dance each other's dance," not in a cycle of appropriation and dilution, not in the easy ways of exoticism, but in exploration of ways to connect to the oldest roots of dance therapy and reconnect to our own dance healing forms that are older than time.

\section{Compliance with Ethical Standards}

Conflict of interest This author declares no conflict of interest.

\section{References}

Adams, M., \& Bell, L. A. (2007). Teaching for diversity and social justice. New York: Routledge, Taylor and Francis.

Back, L., \& Solomos, J. (2000). Theories of race and racism: A reader. New York: Routledge.

Bateson, G. (1972). Steps to an ecology of mind. New York: Ballantine.

Benjamin, L. (Ed.). (1997). Black women in the academy: Promises and perils. Gainesville: University of Florida.

Birdwhistell, R. (1970). Kinesics and context: Essays on body motion communication. New York: Ballantine.

Boas, F. (1944/1972). The function of dance in human society. Brooklyn, NY: Dance Horizons.

Boggs, G. L., \& Kurashige, S. (2012). The next American Revolution: Sustainable activism for the twentyfirst century. Berkeley, CA: University of California.

Bourdieu, P. (1991). Epilogue: On the possibility of a field of world sociology. In P. Bourdieu \& J. Coleman (Eds.), Social theory for a changing society (pp. 373-387). San Francisco: Westview, Russell Sage Foundation.

Caldwell, C. (2013). Diversity issues in movement observation and assessment. American Journal of Dance Therapy, 35(2), 183-200.

Chang, M. (1982). Towards an understanding of the role of ritual dance in dance therapy: A comparison of dance therapy and voodoo (Unpublished master's thesis). City University of New York Hunter College, New York.

Chang, M. (2000). Multicultural difference in dance-movement therapy: Preconference Training Seminar. 35th Annual American Dance Therapy Association Conference, Seattle, WA. October, 2000.

Chang, M. (2002). Cultural congruence and aesthetic adult education: Teaching dance/movement therapy in Seoul, Korea. Dissertation Abstracts International (UMI No. 3052868).

Chang, M. (2015). Cultural consciousness and the global context of dance/movement therapy. In S. Chaiklin \& $\mathrm{H}$. Wengrower (Eds.), The art and science of dance/movement therapy: Life is dance (2nd ed., pp. 317-334). New York: Routledge.

Concepcion, Y. (2015). Afro Puerto Rican Bomba and Afro-Dominican Salve community healing approaches: Implications for DMT theory and practice. (Unpublished master's thesis). Pratt University, New York. 
DeAngelis, T. (2015, Vol 46, No. 3). In search of cultural competence. Retrieved from http://www.apa.org/monitor/2015/03/cultural-competence.aspx

Degruy, J. A. (2005). Post traumatic slave syndrome. http://joydegruy.com/joy-de-gruy-books-cds-anddvds/. Downloaded September 1, 2016.

Dosamantes-Beaudry, I. (1997a). Reconfiguring identity. The Arts in Psychotherapy, 24(1), 51-57.

Dosamantes-Beaudry, I. (1997b). Embodying a cultural identity. The Arts in Psychotherapy, 24(2), $129-135$.

Dosamantes-Beaudry, I. (1999). Divergent cultural self construals: Implication for the practice of dance/movement therapy. The Arts in Psychotherapy, 26(4), 225-231.

Dulicai, D., \& Berger, M. (2005). Global dance/movement therapy growth and development. The Arts in Psychotherapy, 32, 205-216.

Evan, B. (1976). A retrospective outline 1958-1976: Dance, movement, word therapy with the neurotic client as conceived and formulated by Blanche Evan. Self-produced film Blanche Evan, 1976, NY. Available from Blanche Evan Dance Foundation c/o Anne Krantz, 146 5th Avenue, San Francisco, CA 94118.

Greyson, A. (2015, 4 February). United by our differences: DMT and the dance of inclusion in a multicultural and diverse world. In ADTA Webinar Creative Collaboration Series. Retrieved from https://adta.bizvision.com/category/adta-webinars

Hanna, J. (1990). Anthropological perspectives for dance/movement therapy. American Journal of Dance Therapy, 12(2), 115-126.

Hanna, J. (2006). The power of dance discourse: Explanation in self-defense. American Journal of Dance Therapy, 28(1), 3-20.

Hardy, K. http://www.socialwork.career/2015/09/race-matters-how-to-talk-effectively-about-race.html. Retrieved September 26, 2016.

Harris, D. (2010). When child soldiers reconcile: Accountability, restorative justice, and the renewal of empathy. Journal of Human Rights Practice, 2(3), 334-354.

Helpmefindparents. (2013). What kind of Asian are you? [Video file]. Retrieved from https://www. youtube.com/watch?v=DWynJkN5HbQ

Hunter, M. (2007). The persistent problem of colorism: Skin tone, status, and inequality. Sociology Compass, 1, 237-254. doi:10.1111/j.1751-9020.2007.00006.x.

Jenkins-Hayden, L. M. (2011). Movement encounters in Black and White: Understanding issues of race and cultural competency in dance/movement therapy. Master's thesis, Drexel University, Philadelphia, PA. Available from the author http://baadaffinitygroup.weebly.com/thesis-purchasing. html

Jenkins-Hayden, L. M. (2015, 11 February). Black history and the "Black Lives Matter" movementImplications for DMT practice in a supposed "post-racial" society. In ADTA Webinar Creative Collaboration Series. Retrieved from https://adta.bizvision.com/category/adta-webinars

Kealiinohomoku, J. (1983). An anthropologist looks at ballet as a form of ethnic dance. In R. Copeland \& M. Cohen (Eds.), What is dance: Readings in theory and criticism (pp. 533-549). New York: Oxford.

Kendall, F. (2012). Understanding White privilege (2nd ed.). New York: Routledge.

Levy, F. (1992). Dance movement therapy: A healing art, (2nd ed.). American Alliance for Health, Physical Education, Recreation and Dance, 1900 Association Dr., Reston, VA. 22091.

Lomax, A., Bartenieff, I., \& Paulay, F. (1974). Choreometrics: A method for the study of cross-cultural pattern in film. In Comstock, T. (Ed.), CORD Research Annual VI. New Dimensions in Dance Research: Anthropology and Dance: The American Indian (pp. 193-212). New York: Congress on Research in Dance.

Longmore, P. K., \& Umansky, L. (Eds.). (2001). The new disability history: American perspectives. New York: New York University.

Magee, R. V. (in press). Teaching mindfulness with mindfulness of diversity. In McCown, D., Reibel, D., Micozzi, M. (Eds.), Teaching mindfulness: A practical guide for clinicians and educators (2nd ed.). New York: Springer.

Magee, R.V., The Way of ColorInsight: Understanding race and law effectively through mindfulnessbased ColorInsight practices (June 1, 2015). Georgetown Law Journal of Modern Critical Race Perspectives, January 2016; Univ. of San Francisco Law Research Paper No. 2015-19. Available at SSRN: http://ssrn.com/abstract=2638511

Marmot, M. (2005). Social determinants of health inequality. The Lancet, 365(9464), 1099-1104. 
McGoldrick, M., Carter, E. A., \& Garcia-Preto, N. (2011). The expanded family life cycle: Individual, family, and social perspectives. Boston: Pearson Allyn \& Bacon.

McGoldrick, M., Giordano, J., \& Garcia-Preto, N. (2005). Ethnicity and family therapy (3rd ed.). New York: Guilford.

McIntosh, P. (1988). White privilege: Unpacking the invisible knapsack. Working paper 189. White privilege and male privilege: A personal account of coming to see correspondences through work in women's studies. Available from the Wellesley College Center for Research on Women, Wellesley MA 02181.

Meyers, D. T. (1997). Feminist social thought: A reader. New York: Routledge.

Mezirow, J. (1991). Transformative approaches of adult learning. San Francisco: Jossey-Bass.

Nishida, A. (2008). An autoethnography of an international dance/movement therapy student. (Unpublished master's thesis). Chicago: Columbia College.

Pallaro, P. (1997). Culture, self and body-self: Dance/movement therapy with Asian Americans. Arts in Psychotherapy, 24(3), 227-241.

Paulay, F., \& Lomax, A. (1977). Choreometrics: Dance and human history, the longest trail, palm play, step style. Berkeley, CA: University of California Extension, Center for Media and Independent Learning.

Phelps, E., O’Connor, K., Cunningham, W., Funayama, E. S., Gatenby, C., Gore, J., \& Banaji, M. R. (2000). Performance on indirect measures of race evaluation predicts amygdala activation. Journal of Cognitive Neuroscience 12(5): 729-738. Published Version doi: 10.1162/089892900562552. Accessed May 12, 2013 6:30:01 PM EDT Citable Link http://nrs.harvard.edu/urn-3:HUL.InstRepos: 3512208

Picart, C. J. (2013). Critical Race Theory and copyright in American dance: Whiteness as status property. New York: Palgrave Macmillan.

Priest, M. (2008). Salvation is the issue. Meridians Vol. 8, 116-122. Indiana University Press. http://www.jstor.org/stable/40338754

Rankine, C. (2014). Citizen: An American lyric. Minneapolis, MN: Greywolf.

Rivera, Mara. (2008). Healing aspects of Bomba an autoethnographic study (Unpublished master's thesis). New York: Pratt University.

Schelly-Hill, E. \& Goodill, S. (2005). International students in American dance/movement therapy education: Cultural riches and challenges. Presented at the 39th Annual American Dance Therapy Association Conference, Nashville, TN. October, 2005.

Schmais, C. (1999). Marian Chace Annual Lecture groups: A door to awareness. American Journal of Dance Therapy, 21(1), 5-18.

Steele, C. (2010). Whistling Vivaldi: And other clues to the stereotypes that divide us. New York: Norton.

Stock, C. (2001). Myth of a universal dance language: Tensions between globalisation and cultural difference. In S. Burridge (Ed.), Asia Pacific dance bridge: Academic conference, papers and abstracts (pp. 246-262). Singapore: World Dance Alliance.

Sue, D. (2003). Overcoming our racism: The journey to liberation. San Francisco: Jossey-Bass.

Sue, D. W., Capodilupo, C. M., Torino, G. C., Bucceri, J. M., Holder, A. M. B., Nadal, K. L., \& Esquilin, M. (2007). Racial microaggressions in everyday life: Implications for clinical practice. American Psychologist, 62(4), 271-286. doi:10.1037/0003-066X.62.4.271.

Unruh, K. (2011). From kitchen mechanics to jubilant spirits of freedom: Black, working-class women dancing the Lindy Hop. The Journal of Pan African Studies, 4(6), 213-233.

\section{Meg H. Chang}

EdD, BC-DMT, NCC, LCAT- Teaches Mindfulness Based Stress Reduction (MBSR) at the Center For Mindfulness, University of Massachusetts Medical School, Worcester, Massachusetts. Conducted intercultural research in Seoul, Korea and Taipei, Taiwan. Former chair and core faculty at Lesley University in Cambridge, MA and also the Somatic Psychology Program at the California Institute of Integral Studies. Former dance/movement therapy (DMT) faculty at The New School and Pratt University in New York City. Founding member of the ADTA Multicultural and Diversity Committee, two-term National Treasurer, and member of Educational Standards task force. Has practiced DMT in psychiatric facilities, medical settings, in shelters for victims of domestic violence, and in private practice for over 30 years. 